\title{
Mechanical performance of ozone functionalized MWCNTs/PC nanocomposites
}

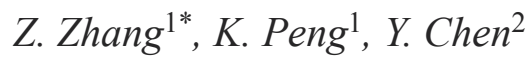 \\ ${ }^{1}$ National Center for Nanoscience and Technology, China, Beijing 100190, China \\ ${ }^{2}$ Institute of Process Engineering, Chinese Academy of Sciences, Beijing 100190, China
}

Received 16 October 2010; accepted in revised form 16 December 2010

\begin{abstract}
Multi-walled carbon nanotubes (MWCNTs) were functionalized by ozone $\left(\mathrm{O}_{3}\right)$ and then melting mixed into polycarbonate (PC) matrix. The effect of $\mathrm{O}_{3}$ functionalization on the mechanical performance was systematically studied. It was found that the modified MWCNTs exhibited improved dispersion and interfacial adhesion to the matrix as evidenced by scanning electron microscope and micro-Raman spectrometer, which were believed to contribute to the enhanced yield strength of MWCNTs/PC nanocomposites.
\end{abstract}

Keywords: polymer nanocomposites, multi-walled carbon nanotubes, ozone functionalization, polycarbonate, mechanical property

\section{Introduction}

Carbon nanotubes (CNTs) have been expected to be an ideal reinforcement for polymers due to their unique one-dimensional structure with good electrical conductivity, robust mechanical and thermal properties [1-3]. Because of their large aspect ratio and high van der Waals interactions, CNTs are normally difficult to be dispersed into polymeric matrices. Meanwhile, their chemical inertness makes them difficult to achieve good interaction with polymers. Chemical functionalizations were shown to be feasible and effective for improving the solubility and dispersion of CNTs. Moreover the functionalized CNTs can provide bonding sites to the polymer matrix so that the adhesion between the polymer and CNTs can be enhanced. So far, the wet chemical modification is the most conventional method to introduce oxygen-containing moieties onto the CNT surface $[4,5]$. However, the liquid wastes generated from these solution-phase oxidation methodologies together with the tedious purifi- cation procedures would greatly limit their further development of applications. Ozone $\left(\mathrm{O}_{3}\right)$ as an environmental friendly route to functionalize CNTs has aroused strong interests for both academia and industry recently [6-9]. One of the most prominent advantages is that this method works under dry conditions without dispersing CNTs into solvents and therefore is convenient for further scale-up. Furthermore, according to our previous study [10], this method can be even carried out at atmospheric pressure and room temperature, leading to comparatively cheaper equipments and lower running costs. Although the oxidation of CNTs by $\mathrm{O}_{3}$ has been extensively studied [6-9], little research has been done so far on the effect of functionalized CNTs to the mechanical performance of polymer matrices, especially for thermoplastics. Some researchers reported the usage of $\mathrm{O}_{3}$ oxidized CNTs by either subsequent grafting of a coupling agent or direct dispersing into epoxy resins $[11,12]$. In this study, we incorporate $\mathrm{O}_{3}$ functionalized multi-walled car-

"Corresponding author, e-mail: zhong.zhang@nanoctr.cn

(c) BME-PT 
bon nanotubes (MWCNTs) into a polycarbonate (PC) matrix by melt mixing. The amorphous PC was chosen since it is known that CNTs may modify the crystalline morphology in semi-crystalline polymers, which may complicate the interpretation of the effect of $\mathrm{O}_{3}$ functionalized MWCNTs.

\section{Experimental}

\subsection{Materials}

The pristine MWCNTs (marked as $p$-MWCNTs in this paper) were prepared by a chemical vapor deposition method with purity $>95 \mathrm{wt} . \%$, average diameter between 10 and $20 \mathrm{~nm}$, and length between 1 and $10 \mu \mathrm{m}$. The PC has a brand name as Macrolon 2800 , with the melt flow index $=9 \mathrm{~g} / 10 \mathrm{~min}$ at $300^{\circ} \mathrm{C}$, and density $\rho=1.2 \mathrm{~g} / \mathrm{cm}^{3}$. Both MWCNTs and $\mathrm{PC}$ were supplied by Bayer MaterialScience AG (Leverkusen, Germany). Before further functionalization or melt-mixing process, the MWCNTs, PC or master-batches were dried at $373 \mathrm{~K}$ overnight within a vacuum oven.

\subsection{Functionalization of MWCNTs}

The MWCNTs were functionalized with $\mathrm{O}_{3}$ at room temperature, which has been discussed in our recent work [10]. Generally, $3 \mathrm{~g}$ of $p$-MWCNTs was placed into a homemade vertical reactor each time. The $\mathrm{O}_{3}$ ( $5 \mathrm{wt} \%$ in $\mathrm{O}_{3} / \mathrm{O}_{2}$ mixture) was continuously passed through the reactor chamber at room temperature during the oxidation process. The reaction time was fixed for 2 or 4 hours, and then the functionalized MWCNTs were defined as 2h-MWCNTs and 4hMWCNTs in this paper.

\subsection{Preparation of nanocomposite}

A master batch of $15 \mathrm{wt} \%$ MWCNTs in PC was produced by the melt-mixing process in a twin screw extruder (HAAKE-Polylab OS, Haake being part of Thermo Scientific). The screw speed was set at $150 \mathrm{rpm}$. All barrels of the extruder were set to a heating temperature of $280^{\circ} \mathrm{C}$ except the barrels of the melting zone which was $270^{\circ} \mathrm{C}$. After extrusion, the PC/MWCNT composites were cooled down in a water bath and then finally granulated with a pelletizer. The master batch was diluted by pure PC to obtain concentrations of 1,3 and $5 \mathrm{wt} \%$ MWCNTs in the matrix. Dog-bone samples were prepared using a HAAKE mini-injection molding machine. The barrel temperature was $300^{\circ} \mathrm{C}$ and the mold temperature was $120^{\circ} \mathrm{C}$, and the injection pressure was 800 bar.

\subsection{Characterization}

Tensile tests were carried out according to a standard methodology of ASTM D638. They were performed using a SANS CMT2000 Tester equipped with an extensometer at a crosshead speed of $1 \mathrm{~mm} / \mathrm{min}$ at ambient temperature. Young's modulus, yield stress, and elongation at break of each sample were obtained based on at least five specimens per sample.

The composite films were prepared by hot press at $290^{\circ} \mathrm{C}$, and the pressure was $5 \mathrm{MPa}$. The final dimension of the film was $5 \times 5 \times 0.1 \mathrm{~mm}^{3}$ (length $\times$ width $\times$ thickness). The Raman spectra were obtained using a Renishaw 2000 MicroRaman spectrometer (Reinshaw, Wotton-under-Edge, UK) with an excitation length of $633 \mathrm{~nm}$. The compressive stresses were produced in the MWCNTs by quenching the composite specimen down to specific temperature using the cooling cell. Quenching was performed by injecting nitrogen gas from a liquid nitrogen reservoir through the thermally isolated cooling cell. The temperatures used in our experiment ranged from $353 \mathrm{~K}$ down to $193 \mathrm{~K}$, with a cooling rate of $10^{\circ} \mathrm{C} / \mathrm{min}$. Thermal equilibrium in each case was obtained by holding the specimen for $10 \mathrm{~min}$ at a constant temperature.

The fracture surface of the composite samples was analyzed using a Hitachi S4800 scanning electron microscope (SEM). The morphology of $\mathrm{O}_{3}$ functionalized MWCNTs was observed using transmission electron microscope (TEM, FEI Tecnai $G^{2}$ F20, FEI, Hillsboro, Oregon, USA).

Fourier transform infrared (FTIR) spectra were recorded on Perkin Elmer Spectrum One spectrometer. The MWCNTs were pressed into pellet with potassium bromide and scanned from 4000 to $800 \mathrm{~cm}^{-1}$ with a resolution of $2 \mathrm{~cm}^{-1}$. Thermogravimetric analysis (TGA) was performed in a Perkin Elmer Diamond thermogravimetric analyzer under nitrogen atmosphere from 30 to $700^{\circ} \mathrm{C}$ at a speed of $20^{\circ} \mathrm{C} / \mathrm{min}$.

The volume resistivity $\left(\rho_{\mathrm{v}}\right)$ was measured on strips $\left(12 \times 10 \times 20 \mathrm{~mm}^{3}\right)$ prepared by compression molding. Four-point fixture combined with a Keithley 4200-SCS electrometer (Keithley, Cleveland, Ohio, USA) was used to measure volume resistance $\left(R_{\mathrm{v}}\right)$ 
of PC/MWCNT composite samples. The $R_{\mathrm{v}}$ was converted to $\rho v$, using Equation (1):

$\rho_{\mathrm{v}}=R_{\mathrm{v}} \cdot \frac{A}{t}$

where $A$ is the effective area of the measuring electrode and $t$ is the specimen thickness.

\section{Results and discussion}

\subsection{Surface functionalization of MWCNTs}

Figure 1 gives the typical FTIR spectra of MWCNTs before and after $\mathrm{O}_{3}$ treatment. For the $p$-MWCNTs,

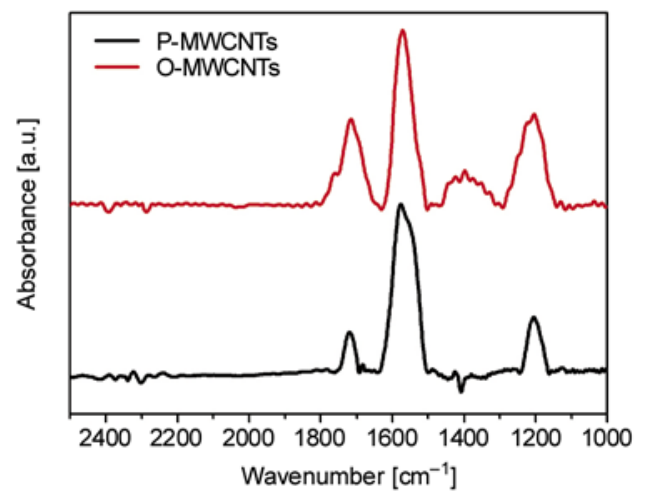

Figure 1. FTIR spectra of the MWCNTs before and after $\mathrm{O}_{3}$ treatment
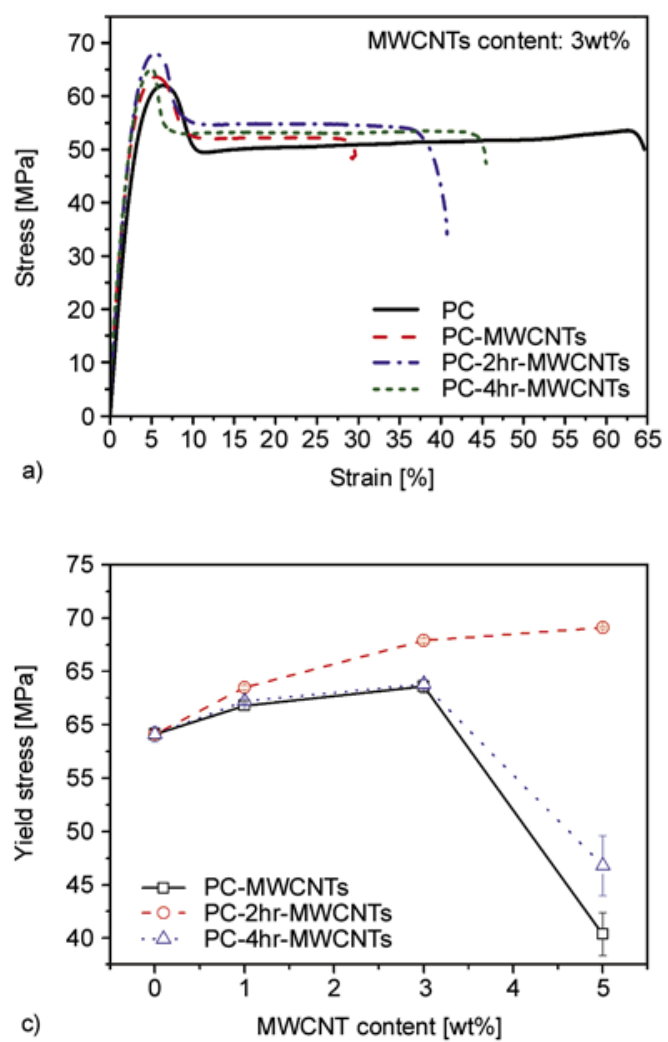

the peak at $1580 \mathrm{~cm}^{-1}$ is assigned to the stretching mode of $v(\mathrm{C}=\mathrm{C})$ of the double bonds in the MWCNT backbone near the surface active sites. After $\mathrm{O}_{3}$ treatment, the intensity of peak around $1720 \mathrm{~cm}^{-1}$ related to carboxylic groups shows an increasing trend, which suggested the MWCNTs were functionalized by treating with $\mathrm{O}_{3}$. The broad band appeared at $1170 \mathrm{~cm}^{-1}$ is attributed to the vibration mode of $v(\mathrm{O}-\mathrm{C}-\mathrm{O})$ of ester or $v(\mathrm{C}-\mathrm{O})$ of carboxylic acid [13].

\subsection{Mechanical property}

Figure 2a shows typical stress-strain curves for the $\mathrm{PC}$ and PC/MWCNT composites at $3 \mathrm{wt} \%$ MWCNT concentration. The values of the elastic modulus as a function of the MWCNT concentration are presented graphically in Figure 2b. Young's modulus of the PC composites visibly increases with increase of MWCNT content regardless of the functionalization. As the MWCNT loadings increase, yield stress of the composite filled with 2h-MWCNTs increased over the range we studied (Figure 2c), whereas yield stress of the composite filled with $p$-MWCNTs decreases at $5 \mathrm{wt} \%$ MWCNT concentration.
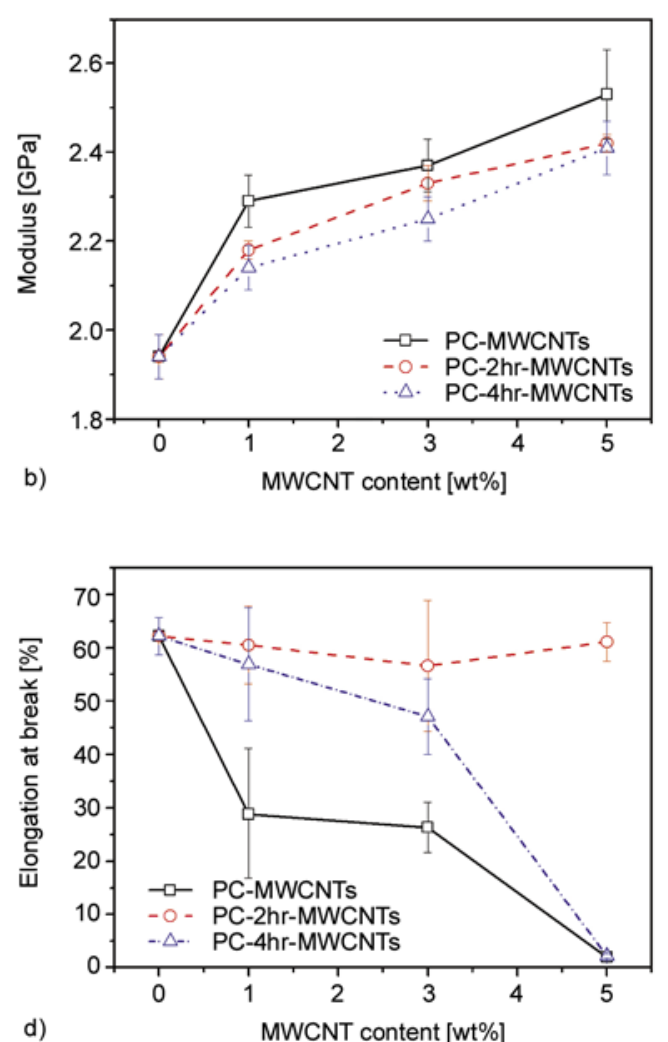

d)

Figure 2. Mechanical properties of MWCNT-filled polycarbonate: (a) stress-strain curves of pure PC and PC/MWCNT composites; (b) (d) elastic modulus, yield stress and elongation at break as a function of MWCNT content for PC-MWCNTs, PC-2h-MWCNTs and PC-4h-MWCNT samples 
Figure $2 \mathrm{~d}$ shows that elongation at break of PC composites reduces significantly from $60 \%$ for neat $\mathrm{PC}$ to $2 \%$ when $p$-MWCNT content is $5 \mathrm{wt} \%$. However, elongation at break of PC-2h-MWCNT composite had no obvious variation. Notably, for the PC-4h-MWCNT composite, the Young's modulus, yield stress and elongation at break show the similar trend, compared with the $p$-MWCNT based composite, which will be discussed further on.

\subsection{Morphology characterization}

The quality of the MWCNT dispersion in the composite is examined by SEM. Usually, good dispersion is necessary for optimal mechanical properties $[14,15]$. Figure 3 shows the SEM images of the fracture surface of composites at $5 \mathrm{wt} \%$ MWCNT concentration, providing some insights of the MWCNT dispersion state. The $p$-MWCNTs are presented mainly in the form of agglomerates, whereas the 2h-MWCNTs are dispersed more uniformly, confirming that $\mathrm{O}_{3}$ treatment can facilitate MWCNT dispersion in PC matrix, as compared in Figure 3a and $\mathrm{b}$. The agglomerates in poorly dispersed composites cause cracks to initiate and propagate easily, and the generated cracks reduce the strength of the composite. On the contrary, well dispersed MWCNTs are more efficient than the aggregated MWCNTs in transferring applied load. Therefore, a significant enhancement in mechanical property of PC-2h-MWCNT composite compared with that of PC-MWCNTs composite is observed.

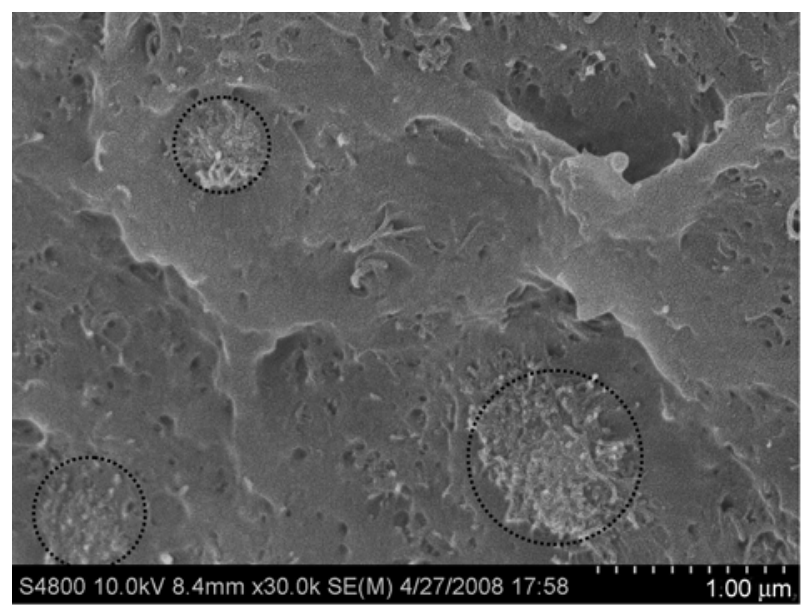

a)

\subsection{Temperature dependent Raman spectroscopy}

Except for the good dispersion, strong interface is also important for CNTs reinforced composite because the external stresses applied to the composite as a whole can be efficiently transferred to the CNTs, allowing them to take a disproportionate share of the load. Due to its sensitivity to the interatomic distance, Raman spectroscopy has been widely used to evaluate the interaction between polymers and CNTs in CNT based composites [16]. Generally, the interaction between CNTs and matrix can be reflected by the Raman shifts of the characteristic peaks $[17,18]$. Figure 4 a shows the most prominent Raman spectra modes of MWCNTs are the $G$-band $\left(1580 \mathrm{~cm}^{-1}\right)$, the $D$-band $\left(1340 \mathrm{~cm}^{-1}\right)$ and the $G^{\prime}$-band $\left(2650 \mathrm{~cm}^{-1}\right)$, exited with $633 \mathrm{~nm}$ laser [19]. According to Wagner's studies [17], the $G^{\prime}$-band was found to be exact and convenient to monitor the temperature-induced strain of CNTs embedded in the polymer. In the present study, we induced a compressive deformation in MWCNTs embedded in the PC matrix by cooling the specimens from 353 to $193 \mathrm{~K}$. As shown in Figure 4b, the $G^{\prime}$-band Raman spectra for 2h-MWCNTs peaked at $2645 \mathrm{~cm}^{-1}$, whereas the $G^{\prime}$-band for 2h-MWCNTs embedded in PC matrix peaks at $2655 \mathrm{~cm}^{-1}$ at $353 \mathrm{~K}$. The higher frequencies shifts were caused by the compression of $\mathrm{C}=\mathrm{C}$ bonds, which resulted from mismatch in the coefficient of thermal expansion between MWCNTs and PC matrix [17]. With

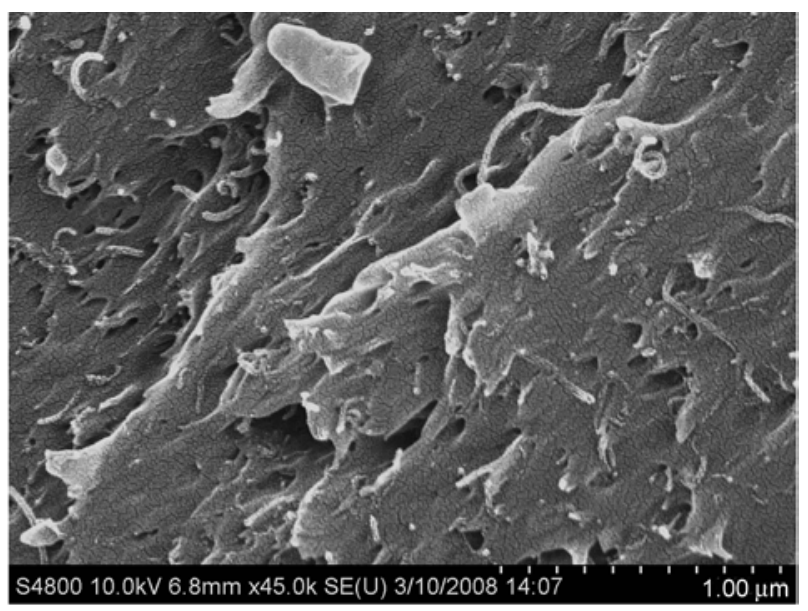

b)

Figure 3. SEM images of composite fracture surfaces showing the dispersion states of MWCNTs. (a) 5 wt $\% p$-MWCNTs; (b) $5 \mathrm{wt} \%$ 2hr-MWCNTs 
a)

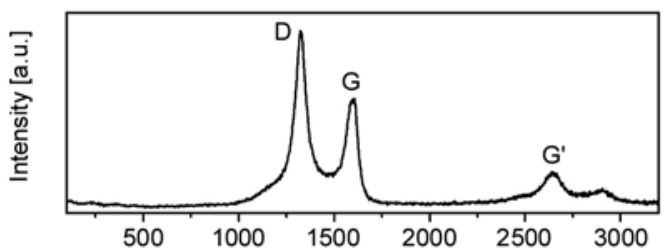

b)
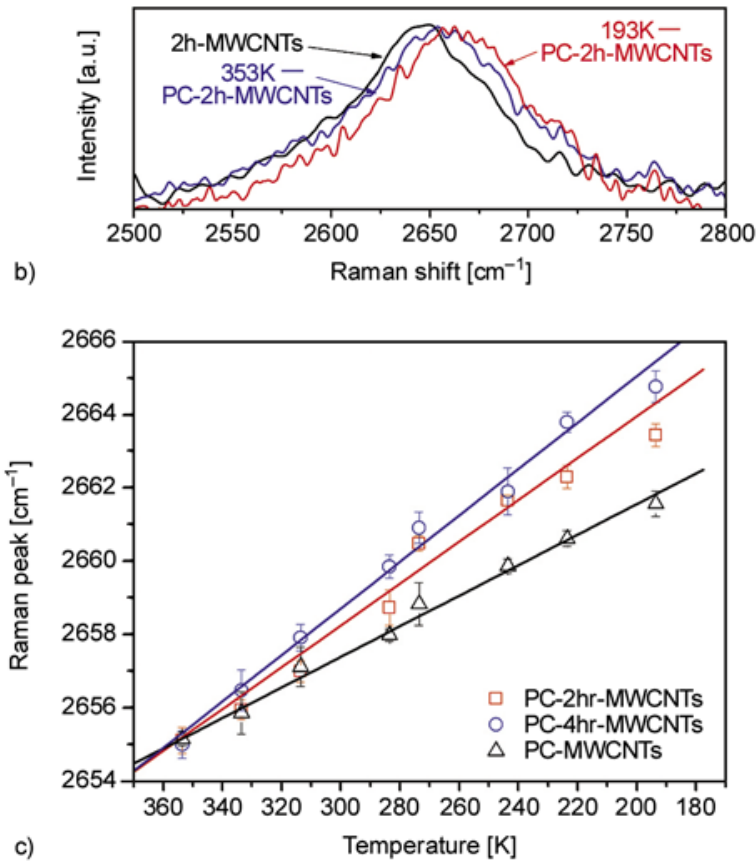

Figure 4. (a) Raman spectra of MWCNTs excited with $633 \mathrm{~nm}$ laser; (b) and (c) effects of embedment and cooling on the frequency shift of the $G^{\prime}$-band of MWCNTs

decreased temperature, the obvious upward shifts of Raman $G^{\prime}$-band peak position for the embedded MWCNTs are expected, and arise from the further shortening of $\mathrm{C}=\mathrm{C}$ bond length due to the compressive stresses from the matrix. As seen in Figure 4c, the cooling of the embedded materials from $353 \mathrm{~K}$

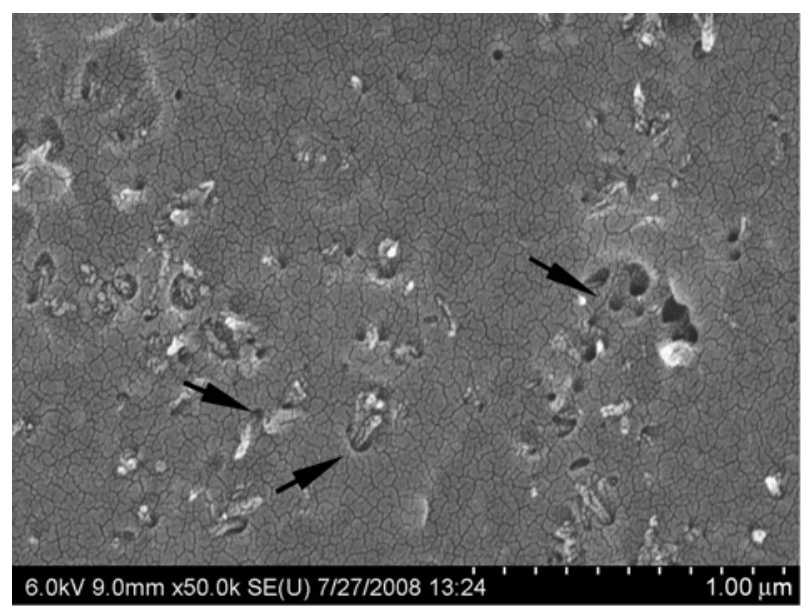

a) down to $193 \mathrm{~K}$ causes 5 and $8 \mathrm{~cm}^{-1}$ shift for $p$-MWCNTs and 2h-MWCNTs, respectively. Comparing with $p$-MWCNT based composite, the $2 \mathrm{~h}$ MWCNTs embedded in PC matrix shows larger $G^{\prime}-$ band shift over the temperature range we studied, illuminating more efficient load transfer between the 2h-MWCNTs and PC matrix. The results also indicate that $G^{\prime}$-band appears larger up-shift with increase of $\mathrm{O}_{3}$ treatment time. By extending $\mathrm{O}_{3}$ treatment time, more functional groups can be attached onto the MWCNT surface [10]. Therefore, with the higher degree functionalization on the nanotube surface, PC-4h-MWCNT composite shows much better load transfer behavior.

Furthermore, the morphology of the fracture surface of MWCNTs based nanocomposites can also reflect the interface status. We can find that many holes exist on the fracture surface of PC-p-MWCNT composite indicated by the arrow in Figure 5a, which means MWCNTs are pulled out of the matrix due to the poor interfacial bonding between $p$ MWCNTs and PC. However, there is no obvious hole on the fracture surface of PC-2h-MWCNT composite (Figure $5 \mathrm{~b}$ ), suggesting improved interfacial adhesion between 2h-MWCNTs and matrix.

\subsection{Thermal stability}

The effect of MWCNT presence on the thermal stability of PC composites is studied by means of TGA in $\mathrm{N}_{2}$ atmosphere, as shown in Figure 6. The temperature corresponding to an initial $5 \%$ of weight loss $\left(T_{5 \%}\right)$, to $50 \%$ of weight loss $\left(T_{50 \%}\right)$, and the temperature of the maximum rate of weight loss ( $T_{\max }$ ) obtained by TGA and by TGA derivative weight curves are given in Table 1. For pure PC, the

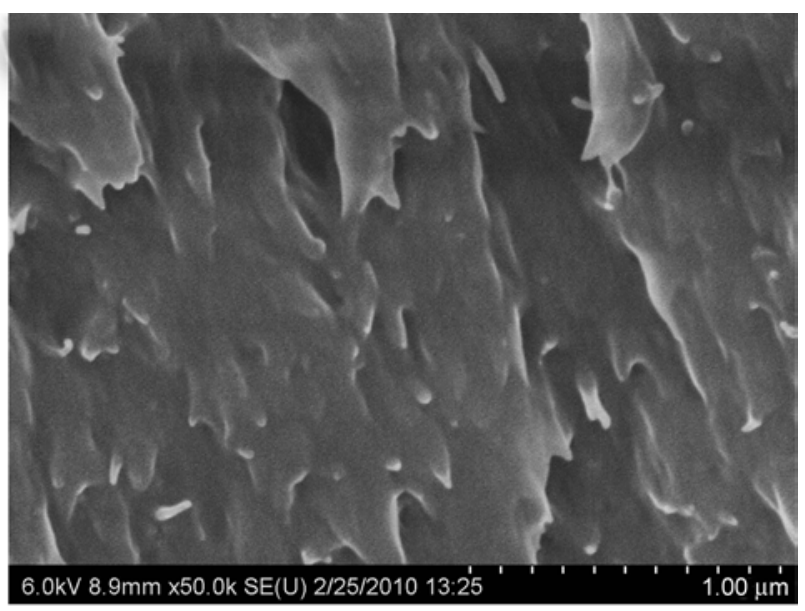

Figure 5. SEM images of composite fracture surfaces: (a) PC-3wt $\%$-MWCNTs; (b) PC-3wt $\%$ - $2 \mathrm{hr}-\mathrm{MWCNTs}$ 

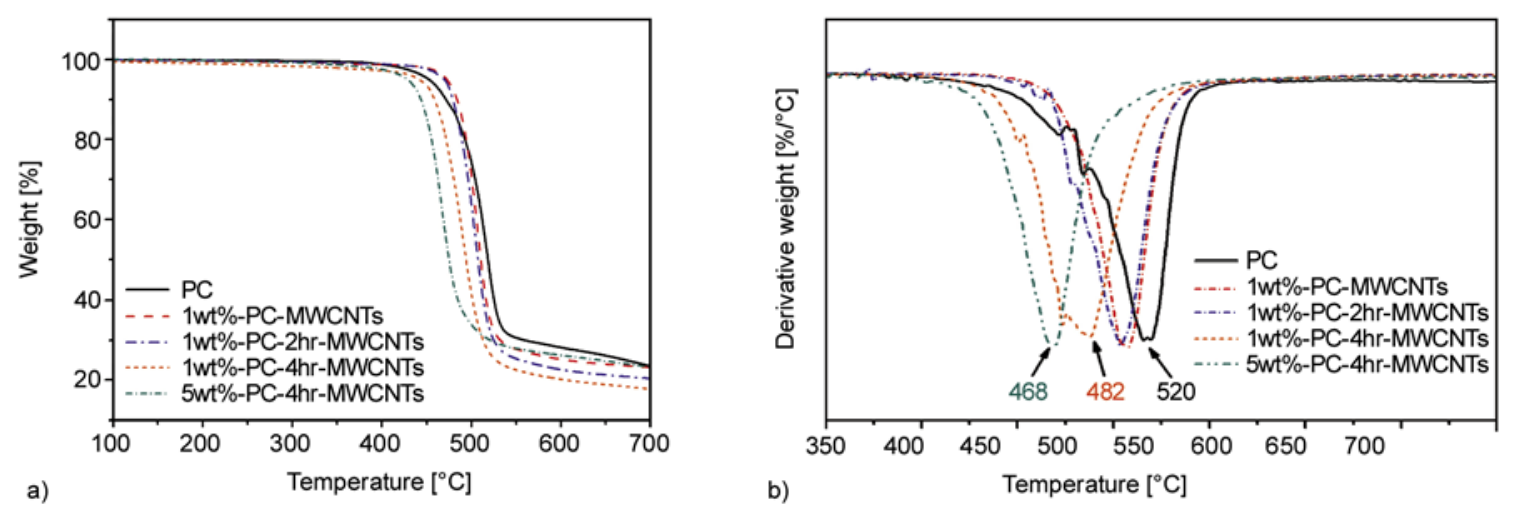

Figure 6. TGA curves of the PC and its composites in $\mathrm{N}_{2}$ atmosphere: (a) weight loss curves; (b) derivate weight curves

Table 1. TGA data of the PC and its composites

\begin{tabular}{|l|c|c|c|}
\hline \multicolumn{1}{|c|}{ Sample } & $\mathbf{T}_{\mathbf{5} \%}\left[{ }^{\circ} \mathbf{C}\right]$ & $\mathbf{T}_{\mathbf{5 0} \%}\left[{ }^{\circ} \mathbf{C}\right]$ & $\mathbf{T}_{\max }\left[{ }^{\circ} \mathbf{C}\right]$ \\
\hline PC & 452 & 518 & 520 \\
\hline PC-1wt\%-MWCNTs & 472 & 510 & 507 \\
\hline PC-1wt\%-2h-MWCNTs & 470 & 507 & 504 \\
\hline PC-1wt\%-4h-MWCNTs & 441 & 494 & 482 \\
\hline PC-5wt\%-4h-MWCNTs & 428 & 474 & 468 \\
\hline
\end{tabular}

thermal stability of nanocomposites from TGA results, we can conclude that the molecular weight of the PC matrix degrades in the presence of MWCNTs, as demonstrated by Pötschke [20].

In order to further explore the effects of different blending processes on the degradation of $\mathrm{PC}$, the major degradation occurs between 460 and $530^{\circ} \mathrm{C}$, and that is followed by a much slower degradation process; $T_{\max }$ is $520^{\circ} \mathrm{C}$. The TGA results indicate that adding MWCNTs and 2h-MWCNTs into the PC matrix can increase the initial decomposition temperature $T_{5 \%}$. However, the $T_{5 \%}$ of PC- $1 \mathrm{wt} \%-4 \mathrm{~h}$ MWCNT composite appears to be lower than that of pure PC, implying worse thermal stability for PC$1 \mathrm{wt} \%-4 \mathrm{~h}-\mathrm{MWCNT}$ composite. The major degradation step for the PC-MWCNTs, PC-2h-MWCNTs and PC-4h-MWCNT composites occur at a much lower temperature. $T_{\max }$ for PC- $1 \mathrm{wt} \%$-MWCNTs, PC-1wt\%-2h-MWCNTs and PC- $1 \mathrm{wt} \%$-4h-MWCNTs are 507, 504 and $482^{\circ} \mathrm{C}$, lower than that of pure PC. Additionally, $T_{\max }$ for PC-5wt\%-4h-MWCNTs is just $482^{\circ} \mathrm{C}$, which evidently decreases as the MWCNT content increase. Due to the depressed

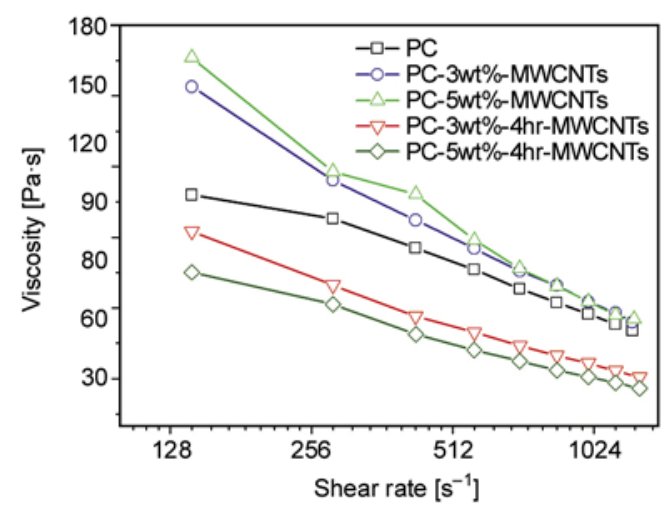

Figure 7. Melt viscosity behavior of composite at $270^{\circ} \mathrm{C}$ melt viscosity behavior during mixing in a Haake Minilab ctw5 is monitored in terms of melt viscosity. The viscosity changes during mixing $\mathrm{PC}$ with MWCNT and mixing PC with 4h-MWCNTs are compared with that of pure PC, respectively. As shown in Figure 7, the melt viscosity of PC-MWCNT composite is obviously higher than that of pure PC at the same shear rate. However, the incorporation of 4h-MWCNTs leads to the decrease of the melt viscosity due to the degradation of PC matrix during the melt mixing. Usually, alcohols and carboxylic acids can lead to molecular degradation through ester interchange. According to Legras's studies [21,22], arylcarboxylate salts can attack the carboxylate groups on the carbonate group through nucleophilic and severely degrade the PC. Therefore, the degradation of PC in our study is due to the carboxylic and carbonyl groups on the MWCNT surface. According to Pötschke's study [20], there are two counteracting effects on mechanical property of composites during the composites prepared by dilution of master-batch: on the one hand, the MWCNT addition can enhance the mechanical property of composite; on the other hand, the degradation of $\mathrm{PC}$ would reduce the mechanical performance. Therefore, the mechanical property of PC-2hMWCNT composite was improved, while as that of PC-4h-MWCNT composite is degraded, as already given in Figure 2. 


\subsection{Electrical conductivity}

The concentration dependencies of $\rho_{\mathrm{v}}$ of PC composites with pristine and surface modified MWCNTs for three types are plotted in Figure 8. It can be seen that all MWCNT based PC composites exhibit a typical percolation behavior. The introduction of MWCNTs to PC decreases the $\rho_{\mathrm{v}}$ of the resulting composites. As shown in Figure 8, the percolation threshold value for PC-MWCNTs and PC-2hMWCNT composites is $1.0 \mathrm{wt} \%$ and reaches up to $5 \mathrm{wt} \%$ for PC-4h-MWCNT composite.

According to $\rho v$ measurement results, the surface modification exhibits a practical effect on them. At the same MWCNT content, the $\rho \mathrm{v}$ of the composite increases with extending $\mathrm{O}_{3}$ treatment time to MWCNTs, as shown in Figure 8. To our knowledge, there are three main requirements for $\rho_{\mathrm{v}}$ of CNTs based composites. These are intrinsic CNT resistance, good dispersion and aspect ratio. Usually, the CNTs show increase in their $R_{\mathrm{v}}$ due to the damage to their intrinsic structures after oxidative treatment $[23,24]$. According to Simmons and co-

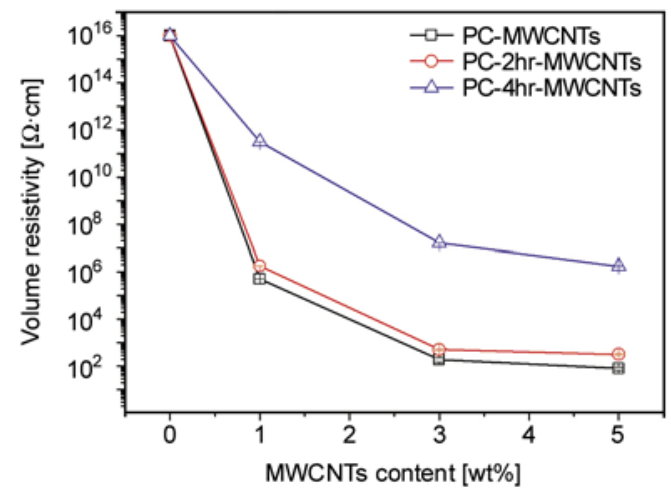

Figure 8. Volume resistivity versus MWCNT content in PC

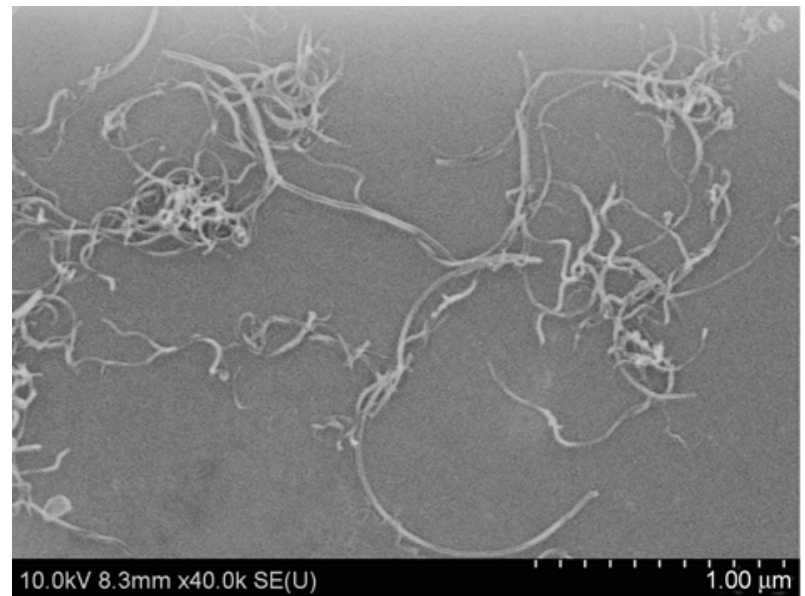

a) worker's study [24], since the $\pi$-conjugated path on the sidewalls of the SWCNTs can be disrupted by $\mathrm{O}_{3}$ treatment, the resistance of SWCNTs increased after oxidation. Therefore, the electrical conductivity of MWCNTs could be lowered after $\mathrm{O}_{3}$ treatment in our case.

To exclude the aspect ratio effect of MWCNTs on $\rho_{\mathrm{V}}$ of composites, the two type MWCNTs are extracted after PC-MWCNTs and PC-4h-MWCNT composites are dissolved in tetrahydrofuran. Both had almost the same aspect ratio, as shown in Figure 9. The morphologies of $p$-MWCNTs, 2h-MWCNTs and $4 \mathrm{~h}-\mathrm{MWCNTs}$ on the carbon grids were observed by TEM, which were extracted from composite. Figure 10 display TEM images of MWCNTs extracted from the PC matrix. From Figure 9a, it can be seen that $p$-MWCNTs keep the same as that of their original. However, from Figure $9 \mathrm{~b}$ and $\mathrm{c}$, it is clear that the $\mathrm{O}_{3}$ modified MWCNT surface is covered by a polymer layer, which should be the PC component. This observation further proves that ester interchange reaction is expected to occur between MWCNTs and PC matrix due to the existence of carboxyl groups on the MWCNT surface. Moreover, according to the statistical analysis, the average thickness of coverage polymer for $2 \mathrm{~h}$ MWCNTs and 4h-MWCNTs are $3.54 \pm 0.35 \mathrm{~nm}$ and $7.38 \pm 1.78 \mathrm{~nm}$, respectively. Apparently, the thickness of polymer layer increases with the increased $\mathrm{O}_{3}$ treatment time of MWCNTs. The polymer layer around MWCNT surface would increase the contact resistance between the MWCNTs, which would impair the conductivity of the composite further. The $\rho_{\mathrm{v}}$ results suggest that the PC-coating could

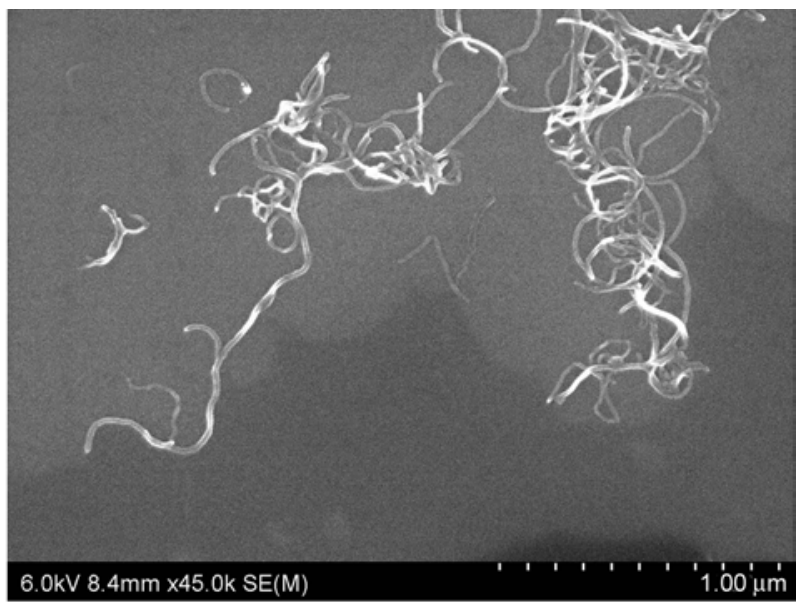

b)

Figure 9. SEM images of MWCNTs extracted from PC/MWCNT composite: (a) PC-MWCNTs; (b) PC-4h-MWCNTs 


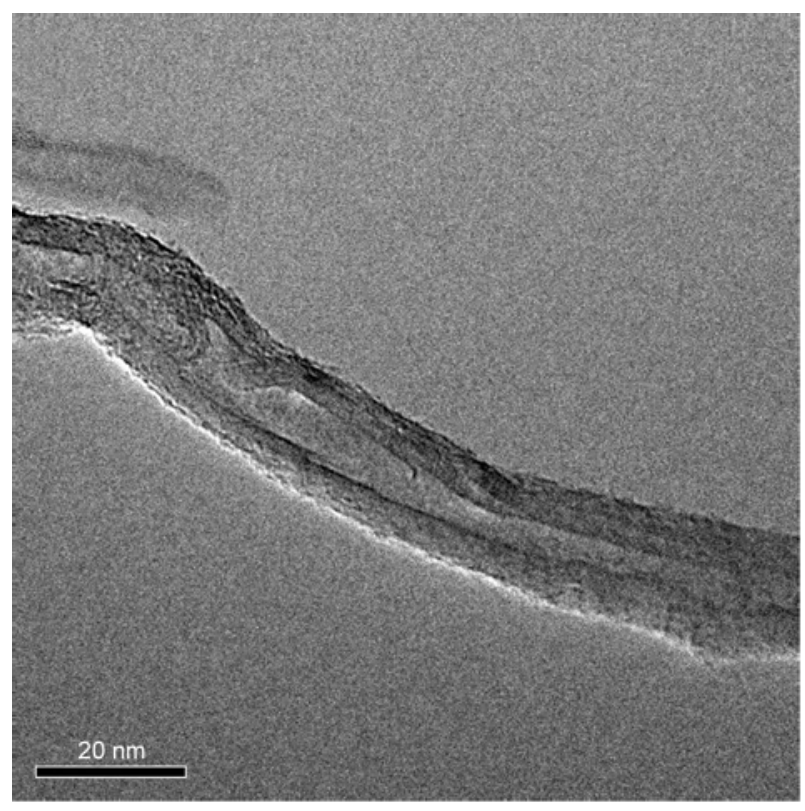

a)

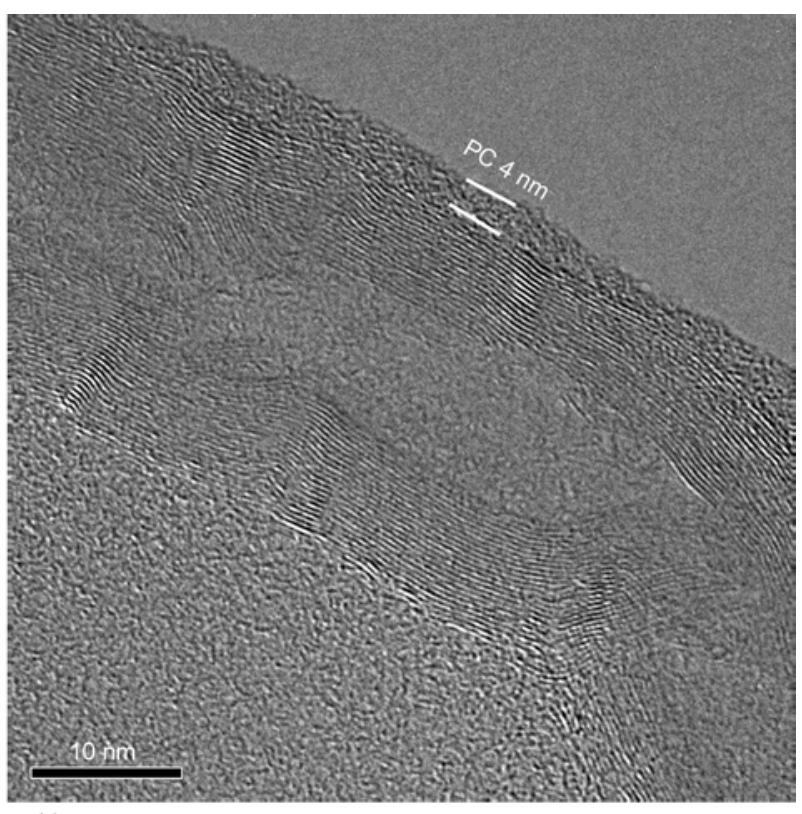

b)

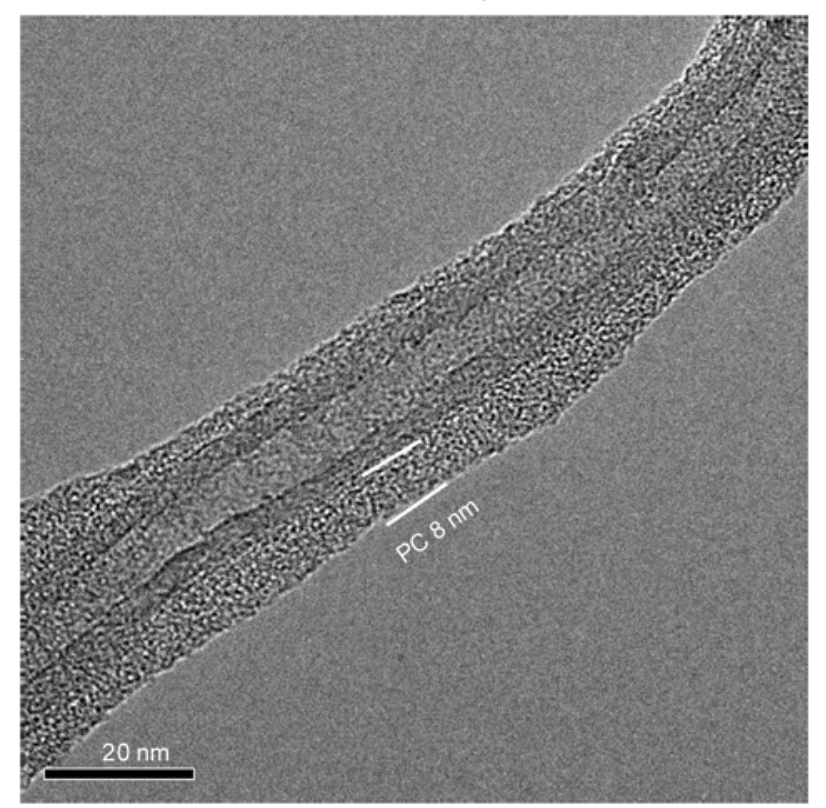

c)

Figure 10. TEM images of MWCNTs extracted from PC/MWCNT composite: (a) PC-MWCNTs; (b) PC-2h-MWCNTs; (c) PC-4h-MWCNTs

effectively insulate the MWCNT surface due to their highly non-conducting property. Additionally, the lower $\rho_{\mathrm{v}}$ value in the case of PC-2h-MWCNTs than that of the PC-4h-MWCNT sample is due to the presence of less amount of PC polymer on the surface of $2 \mathrm{~h}$-MWCNTs.

\section{Conclusions}

Series of as-received and $\mathrm{O}_{3}$ treated MWCNTs based PC composites are prepared by diluting a master-batch containing $15 \mathrm{wt} \%$ MWCNTs using melt mixing. The findings highlighted in this paper may contribute to our understanding on the efficiency of ozonolysis of PC/MWCNT nanocomposites. Therefore, following conclusions can be drawn:

1) Relatively good dispersion is achieved for the $\mathrm{O}_{3}$ treated MWCNTs. A number of 2h-MWCNTs are found to break rather than pull out at the fracture surface, suggesting that strong bonding exists between PC matrix and MWCNTs. The strong interaction between the 2h-MWCNTs and PC matrix would facilitate the load transfer, resulting improved tensile property in their PC matrix. 
2) The thermal stability of PC shows an unusual behavior after adding MWCNTs. According to TGA results, the thermal stability of MWCNT based PC composite reveals a significant decrease after incorporation of $\mathrm{O}_{3}$ treated MWCNTs due to the degradation of PC matrix, especially for 4h-MWCNTs. This effect leads to the decreased mechanical properties.

3) Notably, the results also indicate that the surface modification of MWCNTs as obtained by $\mathrm{O}_{3}$ treatment can influence in the electrical property. The percolation threshold value for PCMWCNTs and PC-2h-MWCNT composites is $1.0 \mathrm{wt} \%$ and reaches up to $5 \mathrm{wt} \%$ for PC- $4 \mathrm{~h}$ MWCNT composite. The $\mathrm{O}_{3}$ treatment does affect the $\rho_{\mathrm{v}}$ negatively due to the change in the MWCNT lattice structure and the formation of a strongly adhered isolating PC layer around the surface of modified MWCNTs.

\section{Acknowledgements}

This project was jointly supported by the National Key Basic Research Program of China (Grant No. 2007CB936803) and a key international collaboration project (Grant No. 2008DFA51220) of the Ministry of Science and Technology of China, a key item of the Knowledge Innovation Project of the Chinese Academy of Science (Grant No. KJCX2-YW-M01) and the National Natural Science Foundation of China (Grant No. 51073044). The authors appreciate Bayer MaterialScience AG for supplying the raw materials.

\section{References}

[1] Wong E. W., Sheehan P. E., Lieber C. M.: Nanobeam mechanics: Elasticity, strength, and toughness of nanorods and nanotubes. Science, 277, 1971-1975 (1997). DOI: $10.1126 /$ science.277.5334.1971

[2] Tans S. J., Verschueren A. R. M., Dekker C.: Roomtemperature transistor based on a single carbon nanotube. Nature, 393, 49-52 (1998).

DOI: $10.1038 / 29954$

[3] Berber S., Kwon Y. K., Tománek D.: Unusually high thermal conductivity of carbon nanotubes. Physical Review Letters, 84, 4613-4616 (2000).

DOI: 10.1103/PhysRevLett.84.4613

[4] Liu J., Rinzler A. G., Dai H., Hafner J. H., Bradley R. K., Boul P. J., Iverson T., Shelimov K., Huffman C. B., Rodriguez-Macias F., Shon Y-S., Lee T. R., Colbert D. T., Smalley R. E.: Fullerene pipes. Science, 280, 12531256 (1998).

DOI: $\underline{10.1126 / \text { science. } 280.5367 .1253}$
[5] Zhang J., Zou H. L., Qing Q., Yang Y. L., Li Q. W., Liu Z. F., Guo X., Du Z.: Effect of chemical oxidation on the structure of single-walled carbon nanotubes. Journal of Physical Chemistry B, 107, 3712-3718 (2003). DOI: 10.1021/jp027500u

[6] Banerjee S., Wong S. S.: Rational sidewall functionalization and purification of single-walled carbon nanotubes by solution-phase ozonolysis. Journal of Physical Chemistry B, 106, 12144-12151 (2002).

DOI: 10.1021/jp026304k

[7] Cai L. T., Bahr J. L., Yao Y. X., Tour J. M.: Ozonation of single-walled carbon nanotubes and their assemblies on rigid self-assembled monolayers. Chemistry of Materials, 14, 4235-4241 (2002).

DOI: $10.1021 / \mathrm{cm} 0202730$

[8] Liu L. V., Tian W. Q., Wang Y. A.: Ozonization at the vacancy defect site of the single-walled carbon nanotube. Journal of Physical Chemistry B, 110, 1303713044 (2006).

DOI: $10.1021 / j p 055999 x$

[9] Byl O., Liu J., Yates J. T.: Etching of carbon nanotubes by ozone - A surface area study. Langmuir, 21, 42004204 (2005). DOI: $10.1021 / 1 \mathrm{a} 040132 \mathrm{~W}$

[10] Peng K., Liu L. Q., Li H. C., Meyer H., Zhang Z.: Room temperature functionalization of carbon nanotubes using an ozone/water vapor mixture. Carbon, 49, 70-76 (2010). DOI: $10.1016 /$ j.carbon.2010.08.043

[11] Choi Y-K., Gotoh Y., Sugimoto K-I., Song S-M., Yanagisawa T., Endo M.: Processing and characterization of epoxy nanocomposites reinforced by cupstacked carbon nanotubes. Polymer, 46, 11489-11498 (2005).

DOI: $10.1016 /$ j.polymer.2005.10.028

[12] Ma P. C., Kim J-K., Tang B. Z.: Effects of silane functionalization on the properties of carbon nanotube/ epoxy nanocomposites. Composites Science and Technology, 67, 2965-2972 (2007).

DOI: 10.1016/j.compscitech.2007.05.006

[13] Mawhinney D. B., Naumenko V., Kuznetsova A., Yates J. T., Liu J., Smalley R. E.: Infrared spectral evidence for the etching of carbon nanotubes: Ozone oxidation at 298 K. Journal of the American Chemical Society, 122, 2383-2384 (2000). DOI: $10.1021 / \mathrm{ja994094s}$

[14] Song Y. S., Youn J. R.: Influence of dispersion states of carbon nanotubes on physical properties of epoxy nanocomposites. Carbon, 43, 1378-1385 (2005).

DOI: $10.1016 /$ j.carbon.2005.01.007

[15] Thostenson E. T., Chou T-W.: Processing-structuremulti-functional property relationship in carbon nanotube/epoxy composites. Carbon, 44, 3022-3029 (2006).

DOI: 10.1016/j.carbon.2006.05.014 
[16] Gao Y., Li L. Y., Tan P-H., Liu L. Q., Zhang Z.: Application of Raman spectroscopy in carbon nanotubebased polymer composites. Chinese Science Bulletin, 55, 3978-3988 (2010).

DOI: $10.1007 / \mathrm{s} 11434-010-4100-9$

[17] Lourie O., Wagner H. D.: Evaluation of Young's modulus of carbon nanotubes by micro-Raman spectroscopy. Journal of Materials Research, 13, 24182422 (1998).

DOI: $10.1557 / J M R .1998 .0336$

[18] Schadler L. S., Giannaris S. C., Ajayan P. M.: Load transfer in carbon nanotube epoxy composites. Applied Physics Letters, 73, 3842-3844 (1998). DOI: $10.1063 / 1.122911$

[19] Rao A. M., Jorio A., Pimenta M. A., Dantas M. S. S., Saito R., Dresselhaus G., Dresselhaus M. S.: Polarized raman study of aligned multiwalled carbon nanotubes. Physical Review Letters, 84, 1820-1823 (2000). DOI: $10.1103 /$ PhysRevLett.84.1820

[20] Pötschke P., Bhattacharyya A. R., Janke A., Goering H.: Melt mixing of polycarbonate/multi-wall carbon nanotube composites. Composite Interfaces, 10, 389 404 (2003).

DOI: $\underline{10.1163 / 156855403771953650}$
[21] Legras R., Mercier J. P., Nield E.: Polymer crystallization by chemical nucleation. Nature, 304, 432-434 (1983).

DOI: $10.1038 / 304432 \mathrm{a} 0$

[22] Bailly C., Daumerie M., Legras R., Mercier J. P.: Kinetics of the thermal degradation of anhydrous bisphenol-A polycarbonate/alkali metal arylcarboxylate systems in the melt. Macromolecular Chemistry and Physics, 187, 1197-1214 (1986). DOI: $10.1002 /$ macp.1986.021870517

[23] Zhang X. F., Sreekumar T. V., Liu T., Kumar S.: Properties and structure of nitric acid oxidized single wall carbon nanotube films. Journal of Physical Chemistry B, 108, 16435-16440 (2004).

DOI: $10.1021 / j p 0475988$

[24] Simmons J. M., Nichols B. M., Baker S. E., Marcus M. S., Castellini O. M., Lee C. S., Hamers R. J., Eriksson M. A.: Effect of ozone oxidation on single-walled carbon nanotubes. Journal of Physical Chemistry B, 110, 7113-7118 (2006).

DOI: $10.1021 / j p 0548422$ 